\title{
EDITORIAL
}

\section{Epidemiology and Infection - Hygiene by another name}

The Journal of Hygiene was founded in 1901. In an introduction published in the first issue the founding editors stated that 'The Journal of Hygiene has been founded in order to meet a need which has long been felt for a journal devoted to the publication in the English language of original work in Hygiene'. They continued by stating that the support that they had received had confirmed them in the opinion that the Journal of Hygiene would 'fulfil a definite purpose by serving as a focus ... for work in Physics, Chemistry, Physiology, Pathology, Bacteriology, Parasitology and Epidemiology, in relation to Hygiene and Preventive Medicine'.

Obviously this grouping of subjects appears a little strange to us now. The Journal publishes little of physies, chemistry and physiology and only those aspects which are relevant to microbial disease. Parasitology was largely separated away with the creation of its own journal within a few years and there are many journals which cater for the more descriptive pathological aspects of disease. Thus of the original-headings listed in the Introduction to the first edition we are left with 'Bacteriology' and 'Epidemiology'. There is no doubt that from the beginning these constituted the mainstream of original work published in the Journal. In the issues of 1901 there were papers on pathogenic microbes in milk, the use of isolation hospitals in controlling scarlet fever, the aetiology of epidemic cerebrospinal meningitis, the modification of toxins with special reference to immunity, an epidemic of typhoid fever and the routine bacteriological examination of water. From a very early stage the Journal has published papers on microbial disease of animals as well as man and the first of these, concerning an outbreak of cattle plague in Shanghai and its limitation by immunization, was published in 1902. In addition we would now use the term 'microbiology' rather than bacteriology to encompass the extensive virology that has been published in the Journal over the years. In fact the first virology paper was published as early as 1902 and it was Walter Reed's paper describing fundamental researches on the aetiology, propagation and prevention of yellow fever. Within this paper lies the essence of the Journal of Hygiene, concerned as it has been with the causative agents of microbial disease and their control.

The need for the Journal is as great as ever but for some time there has been a problem with the use of the word Hygiene in the title. When the Journal was founded, hygiene was used in its proper sense as meaning the science of health. At the time microbial disease dominated the whole of medicine and a contribution to the prevention of microbial disease was a major contribution to health. Thus, that which we now call 'microbiology' was well represented by the word 'hygiene'. However, the word has a different shade of meaning now and the 1986 edition of the Oxford Companion to Medicine states: 'Hygiene is the science and practice of preserving health, in common usage often synonymous with "cleanliness".

I first realized there was a problem with the name of the Journal when I received 


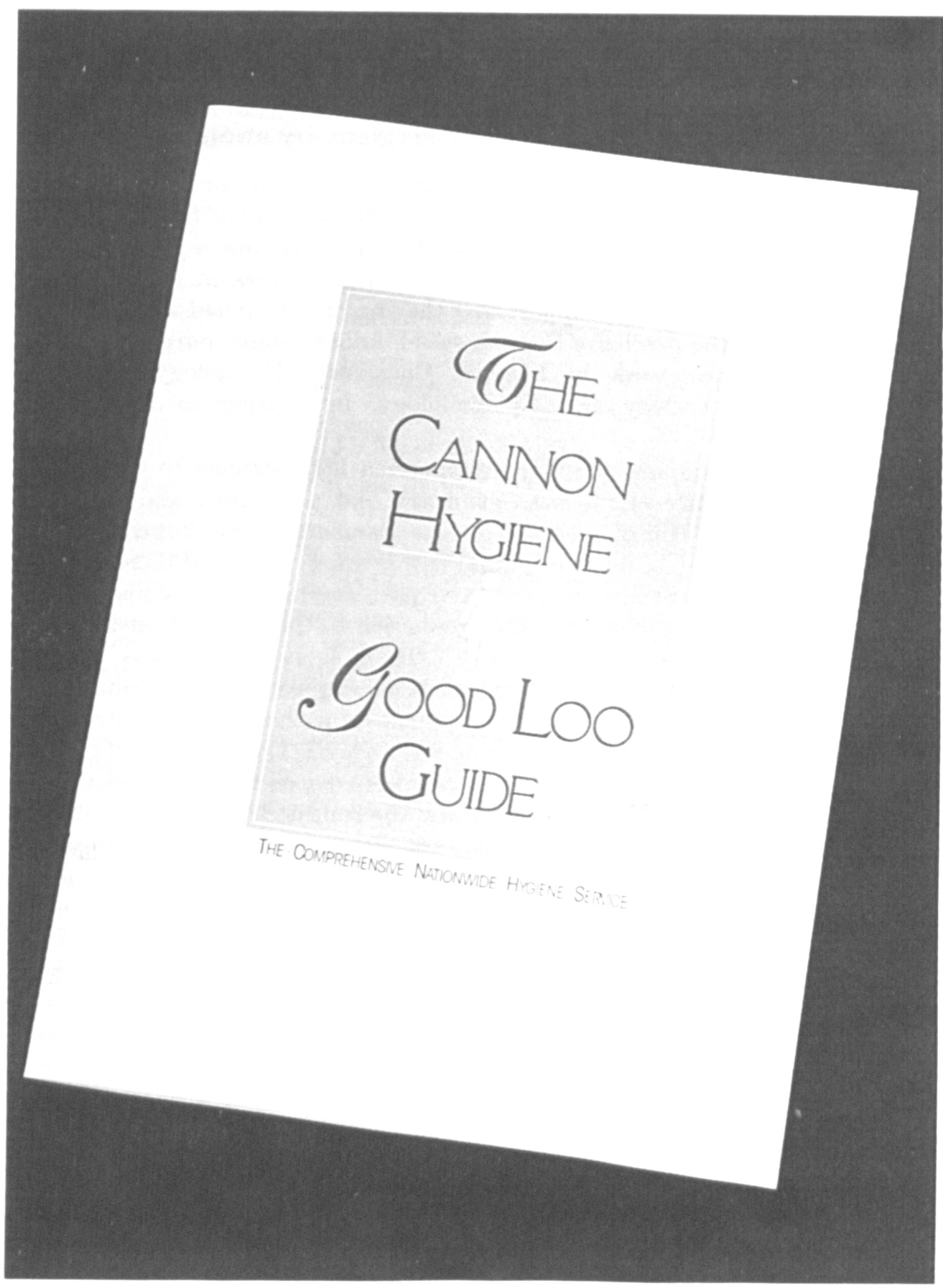


an invitation to lunch at the Ritz Hotel in London. I had never been to the Ritz and immediately began to look forward to it. However, when I realized that I had been invited in my capacity as editor of the Journal of Hygiene to the launch of a new toothpaste I tore up the invitation. Even so, a decision to change the name of a journal is not taken lightly and we have been considering the matter for some time. However, having taken the decision to change the name I was further convinced that we were right to do so when I received notice of the publication illustrated in the photograph opposite.

Choosing a new name was difficult. We have chosen to include the word Infection in the title to indicate that Epidemiology and Infection will continue in the tradition of a broadly based microbiology journal publishing original reports and research concerning the microbial diseases of man and animals. (There will also be regular reviews and editorials.) We include the word Epidemiology to indicate the particular emphasis that the journal has had ever since it was founded, namely a particular interest in the occurrence and spread of microbial diseases. We recognize that this is a central aspect of the subject and necessitates observations on the micro-organisms themselves, clinical aspects, diagnostic techniques, description and analysis of endemic and epidemic disease, the immunology of microbial diseases and their control by measures concerned with immunization, with public health and with hospital hygiene.

It is interesting to note that the journal continues to publish papers on many of the topics which appeared in the first issues of 1901 (e.g. the bacteriology of milk and of water, meningitis, typhoid fever). In addition, wholly new concepts, micro-organisms, diseases and techniques have emerged. For example, issues of the last two years have had contributions on molecular epidemiology, campylobacter infection, legionellosis and the application of polyacrylamide gel electrophoresis. There is no doubt that the need for the journal is greater than ever and the editors are sure that Epidemiology and Infection is a title that will last for a further eighty-six years. 